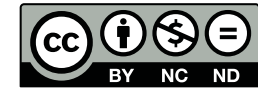

Estudos Teológicos foi licenciado com uma Licença Creative Commons Atribuição - NãoComercial - SemDerivados 3.0 Não Adaptada

http://dx.doi.org/10.22351/et.v58i1.3172

\title{
Mapeamento das Produções aCAdêMicas sobre Ensino Religioso NA REgIão Norte do Brasil ${ }^{1}$
}

\author{
Mapping of academic productions on Religious Education \\ in the Northern region of Brazil
}

\section{Maria Lourdes Sanches Vulcão ${ }^{2}$ Marcos Vinicius de Freitas Reis ${ }^{3}$ Kátia de Nazaré Santos Fonsêca ${ }^{4}$}

\begin{abstract}
Resumo: Este texto visa mapear as produções acadêmicas que discutem a realidade do Ensino Religioso na região Norte. Percebeu-se a escassez de produções científicas sobre o tema na Amazônia e poucos são os trabalhos que discutem a realidade do profissional de Ensino Religioso nesse contexto. A pesquisa foi realizada nos sites do Google Acadêmico, Banco de Teses da CAPES, Portal de Periódicos/CAPES, das universidades públicas e privadas do Brasil e no Curriculum Lattes de pesquisadores e professores que têm envolvimento com a temática religião. Identificou-se que boa parte das produções feitas e publicadas por instituições particulares, mantidas por instituições religiosas, não é adstrita à região Norte.
\end{abstract}

Palavras-chave: Ensino Religioso. Campo religioso amazônico. Educação e religião.

Abstract: This text aims to map the academic productions that discuss the reality of Religious Education in the North. It was noticed the scarcity of scientific productions on the subject in the Amazon and few are the works that discuss the reality of the professional of Religious Education in this context. The research was carried out in the Google Academic sites, CAPES Thesis Repository, Portal of Periodicals / CAPES, Brazilian public and private universities and Curriculum Lattes of researchers and

1 O artigo foi recebido em 27 de novembro de 2017 e aprovado em 13 de maio de 2018 com base nas avaliações dos pareceristas ad hoc.

2 Mestre em Educação - UFG. Professora da Educação Básica. Pesquisadora do Centro de Estudos Políticos, Religião e Sociedade (CEPRES). Presidente da Associação de Professores de Ensino Religioso do Amapá (APERAP), Macapá/Amapá, Brasil. Contato: vulcaoap@hotmail.com

3 Doutor em Sociologia - UFSCar. Professor de História/UNIFAP no Programa de Pós-Graduação Profissional em Ensino de História; no Curso de Especialização em Estudos Culturais e Políticas Públicas e na Graduação em Relações Internacionais da Universidade Federal do Amapá. Coordenador do Grupo Centro de Estudos Políticos, Religião e Sociedade (CEPRES). Contato: marcosvinicius5@yahoo.com.br

4 Mestranda em Educação - PPGED/UNIFAP. Professora de Política e Legislação Educacional Brasileira/ UNIFAP. Membro do Grupo de Pesquisa História, Política e Gestão Educacional (HPGEd/UNIFAP). Contato: katia.fonseca@unifap.br 
professors who are involved with the study of Religion. It was identified that much of the productions made and published by private institutions, maintained by religious institutions, are not affiliated with the North region.

Keywords: Religious Education. Amazonian religious field. Education and Religion.

\section{Introdução}

A Amazônia é conhecida mundialmente por sua diversidade de fauna, flora e também de cultura e religião. A religiosidade se apresenta ali com uma incalculável variedade de mitos, crenças e práticas entre os caboclos, que somada à dos indígenas, “com suas variadas línguas, formas de comportamento, mitos, crenças e etnias teremos uma riqueza ainda maior no que diz respeito à diversidade cultural das populações amazônicas"'5. Depreende-se daí o caldeirão étnico-cultural característico do povo que habita a Amazônia.

Nesse contexto, onde a diversidade cultural se apresenta de forma intensa, o Ensino Religioso (ER) precisa ser estudado e ensinado como fenômeno social, e não como doutrina ou valores morais, como se tem percebido em muitas escolas públicas e particulares na Amazônia. Ensinar a diversidade cultural e religiosa como conteúdos do ER é respeitar a laicidade do Estado e, ao mesmo tempo, evitar intolerância e entender o real lugar das religiões na sociedade.

O presente artigo tem por objetivo mapear as produções acadêmicas que discutem a realidade do ER na região Norte do Brasil. Para a coleta de informações, teve-se acesso aos seguintes sites: Google Acadêmico, Banco de Teses, Portal de Periódicos/ CAPES, das universidades públicas e privadas do Brasil, bem como ao Curriculum Lattes de pesquisadores(as) e professores(as) que têm envolvimento com a temática religião. O texto divide-se em duas sessões: primeiro, discute-se o perfil do profissional do ER na Amazônia e as características de obras que abordam o ER; em seguida, analisa-se o perfil dessas produções dentro da região Norte.

\section{Aspectos históricos e sociais do Ensino Religioso na Amazônia}

A diversidade cultural e étnica da região Norte não tem propiciado um ER diferente de outros estados do Brasil. Em geral, predomina o modelo catequético e proselitista nas escolas públicas, realizado por professores vinculados a matrizes religiosas cristãs. Tal modelo está intrinsicamente ligado à história da disciplina na Amazônia. Segundo Santos 6 , a Igreja Católica manteve nas aulas de ER, nos estados amazônicos, "práticas dos valores cristãos [ministradas] por um profissional credenciado e autorizado pela mesma". Tais práticas dificultam o ensino plural, laico e a diversidade religiosa desse componente curricular.

5 MAUÉS, Raimundo Heraldo. A ilha encantada: Medicina e Xamanismo numa comunidade de pescadores. Belém: EDUFPA, 1990.

6 SANTOS, O Ensino Religioso no Amapá. In: JUNQUEIRA, Sérgio Rogério A. (Org.). Ensino Religioso no Brasil. Florianópolis: Insular, 2015. p. 35-40. 
O agravante dessa situação está, segundo Santos, na formação dos professores, pois nos estados amazônicos, “o ER vem sendo ministrado, na sua maioria, por diversos profissionais das diversas áreas de conhecimento, haja vista a carência da formação específica"’ . Pode-se destacar a exceção dos estados do Pará e Amazonas, que oferecem formação inicial e continuada para professores de ER, uma pela Universidade do Estado do Pará (UEPA) e outra pelo PARFOR. Os demais estados dessa região não têm investido na formação docente para o ER.

Diante do exposto, pode-se afirmar que o ER na região Norte não difere da realidade de outros estados do Brasil. Em geral, o ER catequético e proselitista faz parte do cotidiano nas escolas públicas e é realizado por professores vinculados a matrizes religiosas cristãs, dificultando o ensino plural, laico e a consequente diversidade religiosa que deveria caracterizá-lo. Os docentes que são selecionados a ministrar ER na região Amazônica, em sua maioria, não possuem formação específica - muitos são formados em outras áreas do conhecimento (inclusive Teologia) e poucos possuem conhecimento teórico-metodológico em Ciências da Religião, que os capacitem a ser professores de ER.

Apesar de este estudo ter sido realizado em apenas dois municípios amazônicos, pode-se inferir que tal realidade esteja presente também em outros municípios da região Norte. (Pode-se inferir que tal realidade abrange todos os outros municípios da região Norte.) A pesquisa efetivada no estado do Amapá, entre os anos 2005 a 2008, demonstra a deficitária formação do professor de ER na capital, Macapá, e na cidade de Santana, conforme dados a seguir:

Quadro 1 - Número de professores de ER em Macapá e Santana (2005 a 2008)

\begin{tabular}{|c|c|c|c|c|}
\hline Formação / Ano & 2005 & 2006 & 2007 & 2008 \\
\hline Magistério & 40 & 64 & 23 & 10 \\
\hline Pedagogia & 3 & 7 & 48 & 64 \\
\hline História & 0 & 0 & 0 & 8 \\
\hline Artes & 1 & 35 & 0 & 1 \\
\hline Língua Portuguesa & 0 & 0 & 3 & 4 \\
\hline Filosofia & 0 & 3 & 3 & 3 \\
\hline Ciências Sociais & 0 & 3 & 9 & 6 \\
\hline Psicologia & 0 & 0 & 1 & 0 \\
\hline Teologia & 0 & 2 & 0 & 5 \\
\hline Geografia & 1 & 0 & 0 & 0 \\
\hline Ciências & 0 & 0 & 2 & 0 \\
\hline Ed. Religiosa/Ciências da Religião & 1 & 0 & 1 & 4 \\
\hline Especialização em Ensino Religioso & 0 & 0 & 4 & 4 \\
\hline Não informado & 4 & 0 & 0 & 0 \\
\hline Total & 50 & 131 & 101 & 109 \\
\hline
\end{tabular}

Fonte: VULCÃO, $2016^{8}$

SANTOS, 2015, p. 194.

8 VULCÃO, Maria de Lourdes S. Ensino religioso no Amapá: uma disciplina em construção (2006-2011). 2016. 137 f. Dissertação (Mestrado em Educação) - Universidade Federal de Goiás, Catalão, 2016. 
Ao analisar o Quadro 1, nota-se a diversidade de formação e de professores/as que ministravam a disciplina ER. Aparece apenas um professor com formação em Ciência da Religião, nos anos de 2005 e 2007; nenhum em 2006; e quatro no ano de 2008. Tal realidade, que pode ser explicada pela escassez e até mesmo inexistência de concurso público ao preenchimento de vagas para professor/a da disciplina com formação específica em Ciência da Religião ou em ER.

Os dados ora apresentados são confirmados por uma pesquisa realizada pelo Instituto de Estudos da Religião (ISER), na qual se detectou que a grande maioria de professores/as que atuava no estado do Amapá com ER era ligada à área de "História, Filosofia, e principalmente Pedagogia. [...] Não há no Estado [Amapá] instituição pública que ofereça curso de graduação em Ciência da Religião, Ensino Religioso ou qualquer outro que habilite os professores conforme demanda a norma" .

$O$ resultado da pesquisa do ISER, além de identificar a carência de profissionais habilitados para atuar com o ER, demonstra que as instituições de ensino superior (IES) públicas da região Amazônica oferecem poucos cursos na área, promovem poucos eventos para discutir ER, e também são poucos os grupos de pesquisa sobre a temática de religião ou ER. Somados esses aspectos, tem-se um quadro deficitário que é perpassado pela falta de mão de obra, de investimento em formação por parte do poder público e pelo desinteresse das IES em ofertar cursos que contemplem essa disciplina.

Para se entender melhor a identidade do ER que aqui se defende, recorre-se à sua formação histórica, às legislações que deram legalidade à sua implementação no ambiente escolar, à sua identidade e a seus embates teóricos, políticos, religiosos e educacionais.

O percurso histórico da disciplina ER perpassa e é definido pelos embates de grupos que se fazem presentes nas legislações. Nas Constituições brasileiras de 1891, 1934, 1937, 1946, 1967 e 1988 é possível identificar os interesses que legitimaram sua presença ou ausência nas escolas públicas, nas diferentes épocas. A mobilização de grupos com os mais diferentes posicionamentos em torno do ER vai se formando, fortalecendo e interferindo em maior ou menor apoio político a cada mudança da legislação.

Aqueles que defendem o ER como componente da escola afirmam que a doutrinação tem-se mantido, dentre outros fatores, por falta de formação dos professores para assumir a disciplina. A propósito disso, Sena ${ }^{10}$ afirma que "o Ensino Religioso ficou refém das velhas referências confessionais, entregue aos professores de outras disciplinas, sem formação específica para ministrar aulas nessa área do conhecimento". Nesse caso, é necessário promover cursos de formação inicial e continuada para todos os docentes que estejam em sala de aula.

9 Ver ISER. Mapeamento do Ensino Religioso no Brasil: definições normativas e conteúdos curriculares. 2009. Disponível em: <http://www.ensinoreligioso.seed.pr.gov.br/modules/noticias/print.php?storyid =144>.

10 SENA, Luzia (Org.). Ensino Religioso e a formação docente: Ciências da Religião e Ensino Religioso em diálogo. São Paulo: Paulinas, 2006. p. 22. 
Compreende-se, então, que para ensinar é preciso ter habilidades vinculadas à formação pedagógica. Na afirmação de Tardif, trata-se de "um amálgama, mais ou menos coerente, de saberes oriundos da formação profissional, dos saberes das disciplinas, dos currículos e da experiência"11. O professor ou a professora que não foi formado para atuar em uma determinada disciplina tem dificuldades maiores do que aquele que o foi.

A reforma do ensino promovida pela Lei 5.692/71, Art. $7^{\circ}$, parágrafo único, garantiu a supervisão e o planejamento de ER às igrejas, atribuindo-lhes a responsabilidade em conduzir as atividades da disciplina nas escolas públicas. ${ }^{12}$ Ao analisar a questão, Figueiredo ${ }^{13}$ afirma que essa lei concede posição de destaque ao ER, por acrescentá-lo ao núcleo de disciplinas da Base Nacional Comum, de competência do então Conselho Federal de Educação (CFE). Essa posição fortaleceu seus defensores, os quais iniciaram os Encontros Nacionais do Ensino Religioso (ENER), em 1974, ano que marcou o $1^{\circ}$ ENER, no qual foi definida a implantação do Art. $7^{\circ}$ da Lei 5.692/71, em todos os Estados da Federação; e foi concluída e ratificada a pesquisa e o levantamento de dados cujos resultados seriam publicados, em 1976, na Coleção Estudos da Conferência Nacional dos Bispos do Brasil (CNBB) sobre a Educação Religiosa na escola.

As reflexões e proposições que aconteceram durante os 12 encontros coordenados pelo Grupo de Reflexão do Ensino Religioso (GRERE) sinalizavam a preocupação central de seus realizadores quanto ao caráter não doutrinário e não proselitista da disciplina, embora a presença das autoridades religiosas fosse notória. Junqueira destaca que, no encontro de 1990, em Petrópolis, as preocupações se voltaram aos "desafios da realidade cultural e das novas leis do ensino e, ao mesmo tempo, à busca de metodologias para favorecer uma prática educativa renovada"14. Os encontros aconteciam sem que fosse definida uma data específica para tal. Foi a partir da condução pelo GRERE que se imprimiu uma regularidade de dois anos entre um encontro e outro, sendo um momento em que se desenhava um novo caminho, uma nova identidade para o ER. Conforme já mencionado, eis a apresentação do $5^{\circ}$ ao $12^{\circ} \mathrm{ENER}$, que ocorreram entre 1986 e 1998. Para facilitar a visualização e as comparações entre eles, destacam-se os temas, objetivos, participantes e os principais encaminhamentos advindos de cada encontro, assim como o local que sediou cada um desses eventos, conforme Quadro 2:

11 TARDIF, Maurice. Saberes docentes e formação profissional. Petrópolis: Vozes, 2002. p. 36.

${ }^{12}$ Cf. BRASIL. Lei 5.692, de 11/08/1971, que fixa Diretrizes e Bases para o Ensino de $1^{\circ}$ e $2^{\circ}$ Graus. Disponível em: <http://www.camara. gov.br/sileg/integras/136683.pdf>.

13 FIGUEIREDO, Anísia de Paulo. Ensino Religioso: perspectivas pedagógicas. Petrópolis: Vozes, 1994. p. 88.

14 JUNQUEIRA, Sérgio R. Mapa da produção científica do Ensino Religioso: no período de 1995 a 2010. Curitiba: SIBI; PUCPR, 2013. p. 58. 
Quadro 2 - Encontros de Ensino Religioso (1986 a 1998)

\begin{tabular}{|c|c|c|c|}
\hline \multicolumn{4}{|c|}{ ENCONTRO NACIONAL DE ENSINO RELIGIOSO - ENER } \\
\hline $\mathbf{N}^{\mathbf{0}}$ & Ano & Local & PRINCIPAIS ABORDAGENS \\
\hline $5^{\circ}$ & 1986 & $\begin{array}{c}\text { Brasília } \\
\text { DF }\end{array}$ & $\begin{array}{l}\text { Tema: A visão panorâmica do Ensino Religioso no contexto da } \\
\text { educação. } \\
\text { Objetivos: refletir sobre ER na política educacional vigente, com } \\
\text { vista à nova Constituição. } \\
\text { Participantes: Sem informação. } \\
\text { Encaminhamentos: a natureza e os objetivos do Ensino Religioso, } \\
\text { do Estado e das autoridades religiosas na formação do professor. }\end{array}$ \\
\hline $6^{\mathrm{o}}$ & 1987 & $\begin{array}{c}\text { Brasília } \\
\text { DF }\end{array}$ & $\begin{array}{l}\text { Temas: A situação do Ensino Religioso nos Estados e o seu papel na } \\
\text { educação. } \\
\text { Objetivos: refletir sobre os princípios da educação no contexto } \\
\text { sociopolítico brasileiro, buscar uma linguagem comum quanto ao } \\
\text { Ensino Religioso. } \\
\text { Participantes: } 19 \text { Estados, Distrito Federal e } 2 \text { Territórios federais. } \\
\text { Encaminhamentos: elaboração e entrega de documento aos } \\
\text { constituintes, mobilização nacional, regional e local, organização } \\
\text { local, regional e nacional dos coordenadores e equipes (o GRERE } \\
\text { nacional). }\end{array}$ \\
\hline $7^{\circ}$ & 1988 & $\begin{array}{c}\text { Belo } \\
\text { Horizonte } \\
\text { MG }\end{array}$ & $\begin{array}{l}\text { Tema: A presença do Ensino Religioso na escola brasileira, garantida } \\
\text { pela Constituição. } \\
\text { Objetivos: defesa da escola pública gratuita e de qualidade. } \\
\text { Participantes: professores e coordenadores estaduais do Ensino } \\
\text { Religioso, editoras, representante do CELADEC, bispos responsáveis } \\
\text { pelo Ensino Religioso, assessores da CNBB e membros do GRERE. } \\
\text { Encaminhamentos: carta aberta aos educadores, onde é defendido } \\
\text { o posicionamento dos participantes do ENER (Encontro Nacional do } \\
\text { Ensino Religioso) por uma escola pública, gratuita e de qualidade. }\end{array}$ \\
\hline $8^{\circ}$ & 1990 & $\begin{array}{c}\text { Petrópolis } \\
\text { RJ }\end{array}$ & $\begin{array}{l}\text { Tema: O Ensino Religioso e a dimensão metodológica. } \\
\text { Objetivos: o marco antropológico, a prática pedagógica e o processo } \\
\text { histórico da educação nos últimos anos. } \\
\text { Participantes: } 26 \text { Estados, exceto Tocantins, três bispos, três } \\
\text { assessores da CNBB e um representante da Comissão Evangélica } \\
\text { Latino-Americana de Educação Cristã (CELADEC). } \\
\text { Encaminhamentos: temas como valores, ecumenismo, } \\
\text { interconfessionalidade, interdisciplinaridade, linguagem, formação e } \\
\text { celebração na escola. }\end{array}$ \\
\hline $9^{\circ}$ & 1992 & $\begin{array}{c}\text { São Paulo } \\
\text { SP }\end{array}$ & $\begin{array}{l}\text { Tema: Identidade, conteúdo e linguagem do Ensino Religioso. } \\
\text { Objetivos: Compreender o papel do Ensino Religioso numa } \\
\text { educação interdisciplinar. } \\
\text { Participantes: } 88 \text { pessoas, representantes dos Estados da Federação, } \\
\text { quatro bispos, dois assessores da CNBB e os membros do GRERE. } \\
\text { Encaminhamentos: subsidiar as escolas a promover uma educação } \\
\text { integral e integradora. }\end{array}$ \\
\hline
\end{tabular}




\begin{tabular}{|c|c|c|l|}
\hline $10^{\circ}$ & 1994 & $\begin{array}{l}\text { Tema: O Fenômeno Religioso no Contexto da Pós-Modernidade. } \\
\text { Fortaleza } \\
\text { CE } \\
\text { Objetivos: compreender as mudanças socioculturais, o fenômeno } \\
\text { religioso, as manifestações religiosas, o diálogo inter-religioso e a } \\
\text { prática interdisciplinar. } \\
\text { Participantes: sem informação. } \\
\text { Encaminhamentos: sem informação. }\end{array}$ \\
\hline $11^{\circ} 1996$ & $\begin{array}{l}\text { Tema: O impacto entre a matriz sociopolítica, econômica, cultural e } \\
\text { Beligiosa e as culturas advenientes. } \\
\text { Objetivos: compreender os aspectos sociopolíticos, econômicos, } \\
\text { DF } \\
\text { culturais e religiosos presentes em cada estado. } \\
\text { Participantes: sem informação. } \\
\text { Encaminhamentos: promover a validade, urgência, metas e recursos } \\
\text { disponíveis para os profissionais do Ensino Religioso. }\end{array}$ \\
\hline $12^{\circ}$ & 1998 & $\begin{array}{l}\text { Tema: A correlação do Ensino Religioso e o Projeto Político } \\
\text { Pedagógico da escola. } \\
\text { Objetivos: organizar diretrizes para inserção do Ensino Religioso } \\
\text { no PPP escolar. } \\
\text { Participantes: sem informação. } \\
\text { Encaminhamentos: sem informação. }\end{array}$ \\
\hline
\end{tabular}

Fonte: JUNQUEIRA (2013). Mapa da produção científica sobre ER (1995 a 2010). Adaptado por Vulcão (2016)

Junqueira ${ }^{15}$ observa que a abordagem sobre o fenômeno religioso fez-se presente em 1994, no $10^{\circ}$ ENER/Fortaleza, com o tema "O Fenômeno Religioso no Contexto da Pós-Modernidade, [quando] foram discutidas as mudanças socioculturais e o fenômeno religioso, as manifestações religiosas e o diálogo inter-religioso e a prática interdisciplinar". O interesse pelo termo fenomenológico e a necessidade de se organizar um grupo que tenha isso como bandeira já começaram a ser gestados naquele mesmo ano, embora oficialmente o nascimento de uma entidade para esse fim só tenha ocorrido a partir de 1995, ano de criação do Fórum Nacional Permanente do Ensino Religioso (FONAPER).

Os ENER concentraram-se nas regiões Sudeste, Centro-Oeste e Nordeste. Isso mostra que tais eventos ainda eram limitados a algumas regiões do Brasil, não abrangendo a Amazônia, por exemplo. Não havia preocupação em pensar a identidade do ER na Amazônia e não havia iniciativas. Isso inviabilizava discussão sobre as peculiaridades do fenômeno religioso amazônico. No âmbito do ENER, pensava-se o ER de forma homogênea, desconsiderando as diversidades regionais do Brasil. Para tentar sanar essa lacuna, o estado do Pará, em 1983, instituiu um curso para formar professores de ER e, assim, pensar questões específicas dessa disciplina na Amazônia. Os encontros de formação de professores de ER orquestrados pela Igreja Católica vinham acontecendo em Rondônia, Roraima, Amazonas, Acre, Tocantins e Amapá,

15 JUNQUEIRA, 2013, p. 61. 
como demonstrado na obra "Ensino Religioso no Brasil" organizada por Junqueira ${ }^{16}$. A partir daí esses estados iniciaram seus cursos de formação de professores/as de ER.

\section{Perfil das produções de Ensino Religioso da Amazônia}

Mostrou-se, na seção anterior, que os estados da região Norte não possuem seus encontros de formação para professores e pesquisadores de ER ou de outros temas sobre o fenômeno religioso. Apesar da ampliação no número de eventos, grupos de pesquisas e debates em torno da temática religião e educação ainda são insuficientes, assim como as iniciativas para dar conta da complexidade do fenômeno religioso aplicado à educação na Amazônia brasileira.

Para se entender a importância do ER, deve-se levar em consideração as publicações. Nessa direção, é possível identificar que nos eventos de ER promovidos pela CNBB, universidades públicas e privadas, ou por outros setores da sociedade, havia uma política de incentivo a publicações, e as temáticas em geral eram destinadas a contribuir com a construção do novo paradigma para o ER e para a formação dos professores, contudo pouco se falava sobre a Amazônia. Os encontros criados na região Norte voltados à formação continuada para profissionais do ER tinham a preocupação de discutir questões específicas sobre tal temática, e praticamente não se buscava desenvolver uma política de publicação sobre o ER na Amazônia. Logo, poucos são os trabalhos acadêmicos que discutem a identidade do ER no contexto amazônico.

As primeiras produções tinham uma preocupação com a identidade da disciplina ER de caráter nacional e não levavam em consideração a diversidade regional do Brasil. A obra do Pe. Wolfgang Gruen (1976) ${ }^{17}$ intitulada $O$ Ensino Religioso na Escola Pública inaugura uma nova forma de abordar a disciplina, aplicando uma linguagem não catequética. Posteriormente foi publicada a obra de Anísia de Paulo Figueiredo ${ }^{18}$ intitulada Ensino Religioso: perspectivas pedagógicas, que enfatiza a natureza desse ensino e reflete sobre a definição do papel específico na escola, apontando a distinção entre ER e catequese/doutrinação. Esta, segundo a autora, deve ser concebida como educação permanente da fé e deverá acontecer no ambiente das denominações religiosas, enquanto aquela deverá ocorrer na escola, propiciando entendimento da relação ciência e cultura e fé, na busca por respostas aos questionamentos humanos e seu espaço vital.

Obra de igual destaque, Um paradigma didático para o Ensino Religioso, de Lizete Carmem Viesser ${ }^{19}$, trata da relação pedagógica e defende uma didática apropriada para a disciplina, fazendo um paralelo dos aspectos convergentes entre o ER e

\footnotetext{
${ }^{16}$ JUNQUEIRA (Org.), 2015.

17 GRUEN, Pe. Wolfgang. O Ensino Religioso na escola pública. Belo Horizonte: Universidade Católica de Minas Gerais, 1976.

18 FIGUEIREDO, 1994.

19 VIESSER, Lizete Carmem. Um paradigma didático para o Ensino Religioso. Petrópolis: Vozes, 1994.
} 
os paradigmas newtoniano e cartesiano ${ }^{20}$, em contraste com o holístico ${ }^{21}$. Apesar da distância cronológica, é possível considerar que o Pe. Gruen (1976) e Lizete Viesser (1994) produziram as mais representativas referências sobre o tema, antes da promulgação da LDB/96; e tais produções circularam entre os professores e possibilitaram um importante fato histórico em que o objeto de estudo do ER se deslocou da abordagem da religião, projetando-se para uma vertente histórico-cultural, capaz de gerar um campo de investigação próprio, no contexto pré-LDB. Foram os primeiros passos para a formação do grupo fenomenológico.

Apresentadas algumas das principais obras que dissertam sobre a realidade do ER no Brasil, fez-se o levantamento daquelas que discutem esse tema no contexto da Amazônia. Foram feitas buscas em sites das revistas especializadas nas áreas da Educação, História, Ciência da Religião, Teologia, Sociologia, dentre outras áreas. E também em sites de cursos de pós-graduação focados em temas de religião ou em outros programas de pós-graduação que tenham docentes ou linhas de pesquisa sobre o fenômeno religioso. Recorreu-se ainda ao banco de teses da CAPES, ao Google acadêmico e ao site de periódicos da CAPES.

Tiveram-se dificuldades na coleta das informações, por não haver um local específico de armazenamento de dados sobre a produção acadêmica do Norte do Brasil acerca do tema religião. Encontraram-se três modalidades de produções: dissertações de mestrado (nove), artigos publicados em periódicos (13) e capítulos de livros (três), totalizando 25 produções acadêmicas. Não se localizou nenhuma tese de doutorado e nenhum livro específico sobre o ER na Amazônia, tampouco textos disponíveis na Internet. Alguns textos de anais de eventos constam registrados no Lattes de professores e alunos de educação superior. Os quadros 3, 4 e 5 a seguir indicam as produções, subdivididas em dissertações, artigos em periódicos e capítulos de livros:

20 “As ideias de Isaac Newton e de René Descartes vão confirmar o paradigma newtoniano-cartesiano [...], que se caracteriza pela negação da coexistência dinâmica entre parte e todo; o predomínio da lógica separatista e exclusivista.” Consultar ARAÚJO, Miguel Almir L. de. Abordagem holística na Educação. Revista Sitientibus, Feira de Santana, n. 21, p. 159-176, jul./dez. 1999. Disponível em: <http://www2. uefs.br/sitientibus/pdf/21/ abordagem_holistica_na_educacao.pdf $>$.

${ }^{21}$ Paradigma holístico caracteriza-se por uma abordagem ampla e aberta, que implica novos olhares e percepções nas relações com o universo em sua universidade e possibilita religação com todos os elementos e seres. Disponível em: <http://www2.uefs.br/sitientibus/pdf/21/abordagem_holistica_na_educacao.pdf $>$. 
Quadro 3 - Dissertações sobre ER na região Norte

\begin{tabular}{|c|c|c|c|c|}
\hline \multicolumn{2}{|c|}{ AUTOR } & OBRA & \multirow{2}{*}{ IES/Local } & \multirow{2}{*}{ Ano } \\
\hline Nome & Área & Tema / Título & & \\
\hline $\begin{array}{l}\text { Iracildo Pereira } \\
\text { de Castro }\end{array}$ & Educação & $\begin{array}{l}\text { Tema: Afetividade e Ensino Religioso } \\
\text { Título: Afetividade e mediação do } \\
\text { professor do Ensino Religioso escolar }\end{array}$ & $\begin{array}{c}\text { UEPA } \\
\text { Belém/PA }\end{array}$ & 2008 \\
\hline $\begin{array}{l}\text { Jacilda Barreto } \\
\text { de Araújo }\end{array}$ & $\begin{array}{l}\text { Ciência da } \\
\text { Religião }\end{array}$ & $\begin{array}{l}\text { Tema: Espiritualidade e Ensino Religioso } \\
\text { Título: O Ensino Religioso em Boa } \\
\text { Vista/RR na perspectiva do sentido da } \\
\text { vida: abordagem frankliana }\end{array}$ & $\begin{array}{l}\text { UNICAP } \\
\text { Recife/PE }\end{array}$ & 2013 \\
\hline $\begin{array}{l}\text { José Maria da } \\
\text { Frota }\end{array}$ & $\begin{array}{l}\text { Ciência da } \\
\text { Religião }\end{array}$ & $\begin{array}{l}\text { Tema: Formação Docente } \\
\text { Título: Formação docente para o Ensino } \\
\text { Religioso: o caso de Porto Velho/RO }\end{array}$ & $\begin{array}{c}\text { UNIDA } \\
\text { Vitória/ES }\end{array}$ & 2014 \\
\hline $\begin{array}{l}\text { Edna Maria Biz } \\
\text { Pasini }\end{array}$ & $\begin{array}{c}\text { Ciência da } \\
\text { Religião }\end{array}$ & $\begin{array}{l}\text { Tema: Formação Docente } \\
\text { Título: A dimensão pedagógica } \\
\text { das experiências religiosas: uma } \\
\text { epistemologia a partir da cultura } \\
\text { amapaense }\end{array}$ & $\begin{array}{c}\text { UNIDA } \\
\text { Vitória/ES }\end{array}$ & 2014 \\
\hline $\begin{array}{l}\text { Rodrigo O. dos } \\
\text { Santos }\end{array}$ & Educação & $\begin{array}{l}\text { Tema: Currículo e Ensino Religioso } \\
\text { Título: As diversas abordagens da morte, } \\
\text { do morrer e da finitude no currículo } \\
\text { de formação inicial de professores de } \\
\text { Ensino Religioso/PA }\end{array}$ & $\begin{array}{c}\text { UFPA } \\
\text { Belém/PA }\end{array}$ & 2014 \\
\hline $\begin{array}{l}\text { Elivaldo } \\
\text { Custódio Serrão }\end{array}$ & $\begin{array}{l}\text { Direito } \\
\text { Ambiental } \\
\text { e Políticas } \\
\text { Públicas }\end{array}$ & $\begin{array}{l}\text { Tema: Ensino Religioso no Amapá e } \\
\text { Religiões Africanas } \\
\text { Título: Políticas públicas para a } \\
\text { diversidade cultural: o Ensino Religioso } \\
\text { e as religiões de matrizes africanas no } \\
\text { currículo escolar/AP }\end{array}$ & $\begin{array}{c}\text { UNIFAP } \\
\text { Macapá/AP }\end{array}$ & 2014 \\
\hline $\begin{array}{l}\text { Elaine Costa } \\
\text { Honorato }\end{array}$ & Letras & $\begin{array}{l}\text { Tema: Formação do Professor de Ensino } \\
\text { Religioso } \\
\text { Título: Ensino Religioso: concepções } \\
\text { e práticas pedagógicas no contexto da } \\
\text { escola pública de Rio Branco }\end{array}$ & $\begin{array}{c}\text { UFAC } \\
\text { Rio Branco/ } \\
\text { AC }\end{array}$ & 2015 \\
\hline $\begin{array}{l}\text { Teresa } \\
\text { Felismina Souza }\end{array}$ & $\begin{array}{l}\text { Ciência da } \\
\text { Religião }\end{array}$ & $\begin{array}{l}\text { Tema: Cidadania e Ensino Religioso } \\
\text { Título: O Ensino Religioso na } \\
\text { escola pública de Boa Vista/RR: uma } \\
\text { contribuição epistemológica para a } \\
\text { formação do cidadão e da Cidadania }\end{array}$ & $\begin{array}{l}\text { UNICAP } \\
\text { Recife/PE }\end{array}$ & 2015 \\
\hline $\begin{array}{l}\text { Maria de } \\
\text { Lourdes Vulcão }\end{array}$ & Educação & $\begin{array}{l}\text { Tema: Ensino Religioso no Amapá } \\
\text { Título: O Ensino Religioso no Amapá: } \\
\text { uma disciplina em construção }\end{array}$ & $\begin{array}{c}\text { UFG } \\
\text { Catalão/GO }\end{array}$ & 2016 \\
\hline
\end{tabular}

Fonte: Banco de Teses da CAPES (2017). Adaptação dos autores (2017)

De acordo com as informações trazidas no Quadro 3, detectou-se que as produções tiveram início em 2008 com a dissertação do Iracildo Pereira de Castro, inti- 
tulada Afetividade e mediação do professor do Ensino Religioso escolar. Interessante notar que apenas em 2013, cinco anos depois, é que foi defendido o segundo trabalho, denominado $O$ Ensino Religioso em Boa Vista/RR na perspectiva do sentido da vida: abordagem frankliana. Ambos os estudos, mesmo que tardios, são considerados pioneiros para pensar o ER na região Norte. Esses dois trabalhos, somados às dissertações de Rodrigo Oliveira dos Santos e de Tereza Filismina de Souza, refletem a preocupação com as questões de comportamento, valores, sentido da vida, cidadania, amizade, comportamento humano e afetividade. Isso pode ser explicado pelo fato de que o ER, em muitos municípios amazônicos e em alguns estados, é entendido como o ensino de valores inspirados em concepções cristãs. Logo, discutir esses temas dentro do ER é tentar perceber como as religiões cristãs influenciaram na definição da identidade desse componente curricular no contexto da Amazônia.

Os trabalhos de Elivaldo Custódio, Maria Lourdes Vulcão, Elaine da Costa Honorato, Edna Maria Biz Pasini e José Maria da Frota discutem temas voltados à formação do professor de ER, questões pedagógicas e outros assuntos relacionados à educação. Percebe-se, assim, a ampliação do debate sobre ER a partir de concepções educacionais. Pode-se explicar isso pelo fato de os autores, de alguma forma, terem contato constantemente com a prática docente do profissional de ER nas mais diversas realidades da Amazônia. Tentam mostrar como a disciplina, formação docente e outros aspectos que envolvem o ER carecem de subsídios que o legitimem como elemento importante da escola, tal qual os demais componentes curriculares, e possa então ser pensado a partir do fenômeno religioso.

Na região Norte, o Amapá foi o estado que mais produziu dissertações com temática voltada para o ER local, somando três trabalhos, seguido do Pará e Roraima, com dois cada um, além de Rondônia e Acre com um apenas. Para os estados do Tocantins e do Amazonas não há registro de produções. De todos os trabalhos levantados, cinco dissertações foram realizadas em IES não circunscritas à região Norte, e quatro foram realizadas em universidades situadas na Amazônia. Além disso, as produções estavam adstritas às seguintes áreas: Ciência da Religião e Teologia (quatro), Educação (três), Letras (um), e uma vinculada a programa interdisciplinar.

O número significativo de produções na área de Teologia e Ciência da Religião demonstra o interesse das instituições confessionais em investir nessa área; e a baixa produção em programas de educação mostra o não interesse da área em discutir a temática do ER. Muitos cursos de graduação em Pedagogia, ou outras áreas do conhecimento de ciências humanas, não possuem disciplinas obrigatórias e nem optativas para pensar a formação do professor de ER ou tratar o tema da religião em suas respectivas áreas. Isso significa que é quase nula a formação oferecida pelas licenciaturas, e a baixa produção acerca do fenômeno religioso, sobretudo na Amazônia, leva ao entendimento de que a formação do profissional em ER ou a produção sobre o tema religião são de responsabilidade de instituições religiosas, ou então não reconhecem o ER como elemento da educação formal, como os outros componentes curriculares o são.

$\mathrm{Na}$ amostra aqui apresentada, parte significativa das dissertações foi produzida na área de Ciência da Religião e Teologia, em IES que possuem vínculos estreitos ou 
pertencem a instituições religiosas. O interesse de correntes do catolicismo ou do protestantismo em investir na pesquisa em religião e na formação de profissionais em ER é uma estratégia para manter atrelada a identidade da disciplina ER a suas doutrinas e visões de mundo. Isso tem se representado dentro de IES confessionais como uma medida de legitimação do conhecimento proselitista, que então se reveste de verdade científica.

A falta de investimento das universidades públicas da Amazônia em debater a realidade do ER e da formação do docente para a disciplina tem deixado lacuna para que instituições religiosas o façam. Isso permite que essas definam, por meio de seus cursos de graduação e pós-graduação em Teologia ou Ciência da Religião o perfil do profissional que irá atuar no mercado de trabalho, seja como professor ou pesquisador do ER. Além disso, percebe-se a não iniciativa das secretarias estaduais e municipais de Educação no Brasil em definir a identidade desse componente curricular e os conteúdos a serem ministrados, o que acaba sendo assumido por segmentos religiosos.

Para exemplificar a argumentação, apresenta-se a realidade do Amapá. A única IES que forma profissionais de Ensino Religioso nesse estado é ligada à Assembleia de Deus: a Faculdade de Teologia e Ciências Humanas (FATECH), que possui cursos de graduação em Teologia e de pós-graduação lato sensu em Ciência da Religião e em Ensino Religioso. Os profissionais formados trabalharão nas escolas públicas e privadas do estado, uma vez que a Resolução 14/2006 ${ }^{22}$ estabelece que qualquer graduado com especialização em Ciência da Religião ou Ensino Religioso pode ministrar a disciplina.

No tocante a universidades públicas da Amazônia, detectou-se que apenas a Universidade do Estado do Pará (UEPA) oferece mestrado em Ciência da Religião e licenciatura para habilitar profissionais a ministrarem aulas de ER na educação básica. No site do programa de mestrado encontraram-se informações sobre linhas de pesquisa, tema dos projetos de pesquisa e das dissertações, grupos de pesquisa, áreas de interesse dos professores, eventos e temas discutidos. No referido site não foi localizada nenhuma dissertação sobre o tema do ER. Isso mostra que o programa não dá ênfase à formação docente, mas sim à pesquisa em religião, em conformidade aos interesses de pesquisadores. Tal situação indica que no único programa de pós-graduação stricto sensu em Ciência da Religião localizado na região Norte não há preocupação em pensar a realidade do ER, o que reforça a falta de compromisso institucional para com a formação dos profissionais ligados à docência em ER.

No tocante à publicação de artigos em periódicos, com abordagens sobre o tema religião e educação na região Norte, apresenta-se o Quadro 4:

22 Trata-se de AMAPÁ. Conselho Estadual de Educação. Resolução n. 14, de 15/03/2006, dispondo sobre a oferta do Ensino Religioso no nível fundamental do sistema educacional do estado do Amapá. 
Quadro 4 -Artigos de periódicos sobre Ensino Religioso na região Norte

\begin{tabular}{|c|c|c|}
\hline Titulação / Nome & Tema / Título & Periódico \\
\hline $\begin{array}{l}\text { Ms. Elivaldo } \\
\text { Custódio Serrão }\end{array}$ & $\begin{array}{l}\text { Tema: Religiões africanas } \\
\text { Título: Religiões de matrizes africanas como } \\
\text { patrimônio cultural imaterial no contexto } \\
\text { escolar do Amapá }\end{array}$ & $\begin{array}{l}\text { Revista ALEPH } \\
\text { UFF/RJ (2012) }\end{array}$ \\
\hline $\begin{array}{l}\text { Ms. Elivaldo } \\
\text { Custódio Serrão } \\
\text { Dra. Eugènia Foster }\end{array}$ & $\begin{array}{l}\text { Tema: Religiões africanas } \\
\text { Título: Ensino Religioso e religiões de matrizes } \\
\text { africanas: conflitos e desafios na educação } \\
\text { pública no Amapá }\end{array}$ & $\begin{array}{c}\text { Identidade } \\
\text { EST/RS (2014) }\end{array}$ \\
\hline $\begin{array}{l}\text { Ms. Rodrigo O. dos } \\
\text { Santos } \\
\text { Dr. César Luís Seibt }\end{array}$ & $\begin{array}{l}\text { Tema: Ensino Religioso na Amazônia } \\
\text { Título: Ciências da Religião e o Ensino } \\
\text { Religioso na Amazônia }\end{array}$ & $\begin{array}{c}\text { Revista Pistis \& } \\
\text { Praxis: } \\
\text { Teologia e Pastoral } \\
\text { PUC/PR (2014) } \\
\end{array}$ \\
\hline $\begin{array}{l}\text { Ms. José Maria da } \\
\text { Frota }\end{array}$ & $\begin{array}{l}\text { Tema: Currículo e Ensino Religioso } \\
\text { Título: Ensino Religioso escolar: aspecto legal e } \\
\text { curricular em Porto Velho/RO }\end{array}$ & $\begin{array}{c}\text { Revista Eletr. de } \\
\text { Teologia e Ciências } \\
\text { das Religiões } \\
\text { UNIDA/ES (2014) }\end{array}$ \\
\hline $\begin{array}{l}\text { Ms. Elivaldo } \\
\text { Custódio Serrão } \\
\text { Dr. Remí Klein }\end{array}$ & $\begin{array}{l}\text { Tema: Diálogo inter-religioso } \\
\text { Título: Ensino Religioso e diálogo inter- } \\
\text {-religioso nas escolas públicas: um desafio a ser } \\
\text { enfrentado }\end{array}$ & $\begin{array}{l}\text { Protestantismo em } \\
\text { Revista } \\
\text { EST/RS (2015) }\end{array}$ \\
\hline $\begin{array}{l}\text { Esp. Bruno Rafael } \\
\text { Nascimento }\end{array}$ & $\begin{array}{l}\text { Tema: Modelos epistemológicos } \\
\text { Título: O Ensino Religioso e seus modelos } \\
\text { epistemológicos }\end{array}$ & $\begin{array}{c}\text { Educa/Revista } \\
\text { Multidisciplinar em } \\
\text { Educação } \\
\text { UNIR/RO (2016) }\end{array}$ \\
\hline $\begin{array}{l}\text { Esp. Joezer R. das } \\
\text { Chagas } \\
\text { Esp. Jorge Maurício } \\
\text { da S. Brito } \\
\end{array}$ & $\begin{array}{l}\text { Tema: Epistemologia do Ensino Religioso } \\
\text { Título: O Ensino Religioso em face da } \\
\begin{array}{l}\text { aprendizagem significativa: } \\
\text { epistemológicas e pedagógicas }\end{array} \\
\end{array}$ & $\begin{array}{l}\text { Imagens da } \\
\text { Educação } \\
\text { UEPG/PR (2016) }\end{array}$ \\
\hline $\begin{array}{l}\text { Ms. Elivaldo } \\
\text { Custódio Serrão } \\
\text { Dr. Oneide Bobsin }\end{array}$ & $\begin{array}{l}\text { Tema: Religiões africanas } \\
\text { Título: Ensino Religioso e relações } \\
\text { etnicorraciais: reflexões sobre o currículo } \\
\text { escolar e a implementação da Lei } 10.639 / 2003 \\
\text { na educação pública estadual no Amapá }\end{array}$ & $\begin{array}{l}\text { Numen: Revista de } \\
\text { Estudos e Pesquisa } \\
\text { da Religião } \\
\text { UFJF/MG (2016) }\end{array}$ \\
\hline $\begin{array}{l}\text { Ms. Elivaldo } \\
\text { Custódio Serrão } \\
\text { Ms. Oneide Bobsin } \\
\text { Dra. Eugènia Foster }\end{array}$ & $\begin{array}{l}\text { Tema: Ensino Religioso no Amapá } \\
\text { Título: Repensando o Ensino Religioso na } \\
\text { educação pública estadual no Amapá }\end{array}$ & $\begin{array}{l}\text { Plural/Revista } \\
\text { Estudos Religião } \\
\text { ABHR (2016) }\end{array}$ \\
\hline $\begin{array}{l}\text { Ms. Elivaldo } \\
\text { Custódio Serrão } \\
\text { Dr. Oneide Bobsin } \\
\text { Dr. Marcos Vinicius } \\
\text { de F. Reis }\end{array}$ & $\begin{array}{l}\text { Tema: Ensino Religioso no Amapá } \\
\text { Título: A realidade do Ensino Religioso no } \\
\text { estado do Amapá: proposta de criação do } \\
\text { primeiro curso de licenciatura em Ciência da } \\
\text { Religião }\end{array}$ & $\begin{array}{l}\text { Estudos Teológicos } \\
\text { EST/RS (2017) }\end{array}$ \\
\hline
\end{tabular}




\begin{tabular}{|l|l|c|}
\hline \multicolumn{1}{|c|}{ Titulação / Nome } & \multicolumn{1}{|c|}{ Tema / Título } & Periódico \\
\hline $\begin{array}{l}\text { Ms. Elivaldo } \\
\text { Custódio Serrão }\end{array}$ & $\begin{array}{l}\text { Tema: Religiões africanas } \\
\text { Título: Diversidade cultural e religiosa: o } \\
\text { Ensino Religioso e as religiões de matrizes } \\
\text { africanas na educação escolar }\end{array}$ & $\begin{array}{c}\text { Protestantismo em } \\
\text { Revista } \\
\text { EST/RS (2017) }\end{array}$ \\
\hline $\begin{array}{l}\text { Ms. Elivaldo } \\
\text { Custódio Serrão }\end{array}$ & $\begin{array}{l}\text { Tema: Religiões africanas / Ensino Religioso } \\
\text { Amapá } \\
\text { Título: Ensino Religioso no Amapá: intolerância } \\
\text { contra as religiões de matrizes africanas }\end{array}$ & $\begin{array}{c}\text { Revista Pistis \& } \\
\text { Praxis: Teologia e } \\
\text { Pastoral } \\
\text { PUC/PR (2017) }\end{array}$ \\
\hline $\begin{array}{l}\text { Dr. Marcos Vinicius } \\
\text { de F. Reis }\end{array}$ & $\begin{array}{l}\text { Tema: Ensino Religioso no Amapá } \\
\text { Título: Ensino Religioso no Amapá: um olhar } \\
\text { sobre uma Escola Pública Estadual }\end{array}$ & $\begin{array}{c}\text { Askesis } \\
\text { UFSCar/SP (2017) }\end{array}$ \\
\hline
\end{tabular}

Fonte: Periódicos CAPES e Google Acadêmico. Adaptação dos autores (2017)

De acordo com as informações apresentadas no Quadro 4, observa-se que as produções tiveram início em 2012 com o artigo de Elivaldo Custódio Serrão, intitulado Religiões de matrizes africanas como patrimônio cultural imaterial no contexto escolar do Amapá, registrando-se que a maioria dos trabalhos produzidos sobre o ER no Norte foi realizada por esse pesquisador. Motivado pela complexa realidade das religiões de matrizes africanas no Amapá, marcadas pela intolerância religiosa, fortes vínculos políticos, presença significativa no cenário cultural amazônico, Serrão discute a intersecção das religiões africanas com o ER.

$\mathrm{O}$ estado em que mais se produziram artigos sobre ER foi o Amapá, com 11 trabalhos, seguido do Pará e Rondônia com um trabalho cada. Não se conseguiu achar nenhuma produção nos estados de Tocantins, Roraima, Acre e Amazonas. De todos os artigos levantados, 12 foram publicados em periódicos de IES ou de associação científica fora da região Norte, e um trabalho foi publicado na EDUCA - Revista Multidisciplinar em Educação, da Universidade Federal de Rondônia (UNIR). Além disso, nove artigos foram publicados em periódicos na área de Ciência da Religião/ Teologia, e os outros quatro nas áreas de Educação, História e Sociologia.

O destaque de produções sobre o ER na região Norte é creditado ao estado do Amapá em função de iniciativas de natureza institucional, profissional e social, dentre as quais se destacam: a Universidade Federal do Amapá (UNIFAP), que, por meio do Núcleo de Estudos Afro-Brasileiros (NEAB), desenvolve estudos e pesquisas concernentes a questões étnico-raciais, dentre as quais religiões de matrizes africanas; a Associação de Professores de Ensino Religioso do Amapá (APERAP), que vem ampliando a discussão sobre o ER no Amapá e os movimentos sociais, a exemplo do movimento negro, que têm abordado sistematicamente a temática do ER.

Sobre as ações da APERAP, destaca-se a preocupação de pesquisadores, estudantes e professores vinculados em realizar eventos, palestras e pesquisas acerca de variados temas que envolvem o ER. Por exemplo, o seminário denominado "Educação, Religiosidades e Direitos Humanos", promovido em 2011, com o apoio da Secretaria de Estado de Educação do Amapá (SEED/AP). Outro evento realizado pela referida Associação foi o I Encontro de Pesquisadores e Professores de Ensino Re- 
ligioso do Estado do Amapá, que ocorreu em 2017, em parceria com o Centro de Estudos Políticos, Educação e Sociedade (CEPRES), vinculado ao Curso de Relações Internacionais/UNIFAP. Ressalta-se que esse grupo de pesquisa foi criado em 2013 com o objetivo de impulsionar pesquisas, projetos extensionistas, eventos e propostas relativos ao ER e à intolerância religiosa, e vem dando visibilidade a produções e debates sobre essa disciplina. Além disso, há uma discussão em andamento visando à criação do curso de licenciatura em Ciência da Religião na UNIFAP.

Outro dado interessante a destacar é o fato de, na região Norte, o único periódico especializado na temática religião não ter nenhum trabalho publicado sobre o ER. Trata-se da revista Observatório da Religião, vinculada ao Programa de Pós-Graduação em Ciência da Religião/UEPA, que publicou nos últimos anos importantes trabalhos sobre o tema religião, nas mais diversas interfaces, contudo não entrou no mérito do ER.

Em reforço à ideia esboçada anteriormente, de que as IES públicas não estão preocupadas com a discussão sobre o ER, demonstra-se no quadro a seguir a diminuta produção bibliográfica relativa ao assunto em tela, disponível nos dois últimos anos:

Quadro 5 - Capítulos de livros abordando Ensino Religioso na região Norte (2015-2017)

\begin{tabular}{|c|c|c|}
\hline Nome & Área / Tema / Título & Dados da obra \\
\hline $\begin{array}{l}\text { Dr. Marcos Vinicius de } \\
\text { F. Reis } \\
\text { Esp. Kátia dos Anjos }\end{array}$ & $\begin{array}{l}\text { Área: Gênero e Diversidade na Escola } \\
\text { Tema: Ensino Religioso no Amapá } \\
\text { Título: A concepção do Ensino Religioso } \\
\text { na Escola Estadual Dias da Costa: uma } \\
\text { perspectiva dos anos de 2015/2016 }\end{array}$ & $\begin{array}{l}\text { Diversidade e o } \\
\text { campo da educação: } \\
\text { relatos de pesquisa. } \\
\text { Macapá/AP: Editora } \\
\text { da UNIFAP, } 2017 .\end{array}$ \\
\hline $\begin{array}{l}\text { Ms. Camila Lippi } \\
\text { Ms. Aldeci Dias }\end{array}$ & $\begin{array}{l}\text { Área: Gênero e Diversidade na Escola } \\
\text { Tema: Ensino Religioso no Amapá } \\
\text { Título: O credo da Escola: a negação dos } \\
\text { Direitos Humanos na prática pedagógica } \\
\text { dos professores de Ensino Religioso nas } \\
\text { Escolas Estaduais José Alencar e Deuzuite } \\
\text { Cavalcante, em Macapá/AP }\end{array}$ & $\begin{array}{l}\text { Diversidade e o } \\
\text { campo da educação: } \\
\text { relatos de pesquisa. } \\
\text { Macapá/AP: Editora } \\
\text { da UNIFAP, } 2017 .\end{array}$ \\
\hline $\begin{array}{l}\text { Ms. Maria de Lourdes } \\
\text { S. Vulcão } \\
\text { Esp. Kátia de Nazaré } \\
\text { S. Fonsêca }\end{array}$ & $\begin{array}{l}\text { Área: Educação } \\
\text { Tema: Ensino Religioso no Amapá } \\
\text { Título: Ensino Religioso em um país laico: } \\
\text { entre a Ciência e a Fé }\end{array}$ & $\begin{array}{l}\text { Diversidade e o campo } \\
\text { da educação: diálogos } \\
\text { sobre (in)tolerância re- } \\
\text { ligiosa. Macapá/AP: } \\
\text { Editora da UNIFAP, } \\
2017 .\end{array}$ \\
\hline
\end{tabular}

Fonte: Currículos Lattes das pesquisadoras mencionadas e dos pesquisadores mencionados. Adaptação dos autores (2017)

De acordo com as informações trazidas no Quadro 5, os únicos capítulos de livros voltados ao ER foram produzidos no estado do Amapá, totalizando três produções. Os temas das referidas obras giraram em torno do ER e de sua relação com o Estado laico; da identidade da disciplina a partir da epistemologia fenomenológica, bem como da prática docente. Os estudos apontaram ações nas escolas públicas ama- 
paenses que ferem a laicidade do estado, a exemplo de: prática de ensino catequético; exigência de rezar a oração do Pai-Nosso e de executar canções religiosas; além da negligência quanto ao ensino da cultura africana.

Destaca-se que as discussões levantadas foram construídas no âmbito do curso de especialização em Gênero e Diversidade na Escola, bem como advieram das atividades do grupo de pesquisa CEPRES/UNIFAP e contaram com o financiamento do ministério da Educação. Trata-se de produções recentes, o que confirma que, mesmo a UNIFAP existindo há 27 anos e tendo uma tradição em formar profissionais nas licenciaturas, data de pouco tempo a preocupação com o profissional de ER.

Da análise apresentada a partir dos Quadros 3, 4 e 5 depreende-se que nos estados de Tocantins e Amazonas a produção em torno do ER é nula. Quanto ao Amapá, Pará, Roraima, Rondônia e Acre, não obstante o desenvolvimento de estudos e eventos que se vêm realizando sobre o tema, as publicações ainda são incipientes, independentemente da sua modalidade de produção, apesar de se tratar de assunto tão importante para a educação brasileira.

\section{Considerações finais}

O objetivo deste artigo foi fazer um levantamento de todas as produções científicas sobre o ER na região Amazônica. Concluiu-se que a maioria dos trabalhos publicados foi em periódicos e dissertações em instituições de ensino superior ou em revistas não localizadas na Amazônia e vinculadas a programas de pós-graduação em Teologia ou Ciência da Religião ligados a instituições religiosas. Isso demostra um descaso para com a temática do ER por universidades públicas e a forte presença das matrizes religiosas cristãs como protagonistas para pensar a identidade do ER no Brasil, bem como a formação dos professores dessa disciplina. Discutir o ER em uma instituição pública é garantir que esse componente curricular seja pensado de forma que não fira a laicidade do Estado, atenda à diversidade cultural e religiosa do Brasil e ainda produza um conhecimento para entender a ação das religiões e as diferentes manifestações da religiosidade em âmbito local, regional, nacional e internacional.

Vive-se atualmente uma das maiores crises políticas, econômicas e sociais no Brasil desde o fim da ditadura militar. Percebe-se no parlamento o aumento da representação política de religiosos fundamentalistas e o desmonte das políticas públicas voltadas a grupos de lésbicas, gays, bissexuais, transexuais, travestis, transgêneros, intersexuais, mulheres, índios, negros, quilombolas e deficientes. Não são raros os momentos em que meios de comunicação veiculam cortes em investimentos nas áreas sociais, educacionais e na segurança pública, e noticiam o aumento da corrupção no país.

Nesse contexto, o ER poderia ser utilizado para levar os alunos a refletirem como o fenômeno religioso tem o potencial de alterar o nível das relações interpessoais, não somente na esfera intra como extraescolar, em consonância com a mobilização dos estudiosos do tema para firmar o ER como circunscrito às Ciências da Religião. Contudo, essa luta histórica sofreu um revés com a recente manifestação 
do Supremo Tribunal Federal ${ }^{23}$, quando, em acolhimento à ADI n. 4439/2017, manifestou-se pela retomada à tendência confessional do ER, assumindo uma postura anacrônica para com a formação cidadã, ética e solidária de crianças e adolescentes.

Por conseguinte, urge que se fortaleça a Ciência da Religião como referência da disciplina ER. Nesse caso, a academia precisa ofertar cursos nessa perspectiva, bem como fomentar mais pesquisas nessa área, pois, para que o ER fenomenológico se efetive, é imprescindível a formação de profissionais capazes de reconhecer no fenômeno religioso o conhecimento produzido pela humanidade, o qual possibilita a compreensão da religião pelo aspecto cultural e social. Ademais, é imprescindível o apoio do poder público no sentido de assumir a disciplina, como já o faz com as demais que compõem o currículo escolar, subsidiando docentes com formação inicial e continuada, livros didáticos, além de carga horária que possibilite um trabalho didaticamente favorável. O ER é parte do ensino e não um ensino à parte, precisando, portanto, de um olhar a partir da escola e não dos interesses confessionais das instituições religiosas.

O resultado do mapeamento realizado sobre as produções amazônicas acerca do ER leva à percepção de que maior do que o poder doutrinário das religiões é a inércia do Estado, do poder público e das instituições de ensino superior frente a tal questão. Essas instâncias terminam se movendo por interesses políticos ou convicções ideológicas, e assim ignoram uma realidade que está ao seu redor e enxergam as coisas apenas pelo crivo das vaidades de grupos fechados, deixando de lado a sociedade e suas mazelas, sejam elas sociais, políticas, culturais e/ou educacionais.

Apesar da escassez de trabalhos revelada pelo levantamento efetuado, as poucas produções catalogadas apontam no sentido de que há um embrião em favor de um novo ER, disposto a barrar as investidas dogmáticas na educação, e que há de ser fortalecido. Trata-se de um passo significativo diante da longa caminhada que desafia os que ousam trilhar nela. Por isso há necessidade de que mais pesquisas venham a ser realizadas no âmbito dessa temática na região Amazônica, ficando a contribuição deste estudo como aporte para reflexão sobre o assunto, sem mais tardar.

\section{Referências}

AMAPÁ. Conselho Estadual de Educação. Resolução n. 14, de 15/03/2006. Dispõe sobre a oferta do Ensino Religioso no nível Fundamental do sistema educacional do Estado do Amapá. Publicada no Diário Oficial do Estado [do] Amapá. Macapá, 26 mar. 2006.

BRASIL. Constituição da República dos Estados Unidos do Brasil (1891). Disponível em: $<$ http://www2.camara.leg.br/legin/fed/consti/1824-1899/constituicao-35081-24-fevereiro-1891-532699-publicacaooriginal-15017-pl.html $>$.

. Constituição da República dos Estados Unidos do Brasil (1934). Disponível em: <http:// www.planalto.gov.br/ccivil_03/constituicao/constituicao34.htm>.

${ }^{23}$ Consultar manifestação do Supremo Tribunal Federal na Ação Direta de Inconstitucionalidade (ADI) 4439/2017. Disponível em: <http://www.stf.jus.br/portal/cms/verNoticiaDetalhe.asp?=357099>. 
BRASIL. Constituição dos Estados Unidos do Brasil (1946). Disponível em: <http://www2. camara.leg.br/legin/fed/consti/1940-1949/ constituicao-1946-18-julho-1946-365199-republicacao-1-pl.html>.

. Lei 5.692, de 11/08/1971. Fixa Diretrizes e Bases para o Ensino de $1^{\circ}$ e $2^{\circ}$ Graus. Disponível em: <http://www.camara. gov.br/sileg/integras/136683.pdf>.

Supremo Tribunal Federal. Ação Direta de Inconstitucionalidade (ADI) 4439, de 27/09/2017. Disponível em: <http://www.stf.jus.br/portal/cms/verNoticiaDetalhe.asp?=357099>. FIGUEIREDO, Anísia de Paulo. Ensino Religioso: perspectivas pedagógicas. Petrópolis: Vozes, 1994.

1995.

O Ensino Religioso no Brasil: tendências, conquistas e perspectivas. Petrópolis: Vozes,

GRUEN, Pe. Wolfgang. O Ensino Religioso na escola pública. Belo Horizonte: Universidade Católica de Minas Gerais, 1976.

INSTITUTO DE ESTUDOS DA RELIGIÃO (ISER). Mapeamento do Ensino Religioso no Brasil: definições normativas e conteúdos curriculares. 2009. Disponível em: <http://www. ensinoreligioso.seed.pr.gov.br/modules/noticias/print.php?storyid=144>.

JUNQUEIRA, Sérgio Rogério (Org.). Ensino Religioso e sua relação pedagógica. Petrópolis: Vozes, 2002.

. História, legislação e fundamentos do Ensino Religioso. Curitiba: IBPEX, 2008.

. Mapa da produção cientifica do Ensino Religioso: no período de 1995 a 2010. Curitiba:

SIBI; PUCPR, 2013.

(Org.). Ensino Religioso no Brasil. Florianópolis: Insular, 2015.

MAUÉS, Raimundo Heraldo. A ilha encantada: Medicina e Xamanismo numa comunidade de pescadores. Belém: EDUFPA, 1990.

OLIVEIRA, Lilian Blanck de et al. (Org.). Ensino Religioso: no Ensino Fundamental. São Paulo: Cortez, 2007.

SENA, Luzia (Org.). Ensino Religioso e a formação docente: Ciências da Religião e Ensino Religioso em diálogo. São Paulo: Paulinas, 2006.

SANTOS, Rodrigo Oliveira dos. O Ensino Religioso no Amapá. In: JUNQUEIRA, Sérgio Rogério A. (Org.). Ensino Religioso no Brasil. Florianópolis: Insular, 2015. p. 35-50.

TARDIF, Maurice. Saberes docentes e formação profissional. Petrópolis: Vozes, 2002.

VIESSER, Lizete Carmem. Um paradigma didático para o Ensino Religioso. Petrópolis: Vozes, 1994.

VULCÃO. Ensino religioso no Amapá: uma disciplina em construção (2006-2011). 2016. 137 f.

Dissertação (Mestrado em Educação) - Universidade Federal de Goiás, Catalão, 2016. 